University of Nebraska - Lincoln

DigitalCommons@University of Nebraska - Lincoln

Biological Systems Engineering: Papers and

Publications

Biological Systems Engineering

2005

\title{
Modeling of Bubble Growth Dynamics and Nonisothermal Expansion in Starch-Based Foams During Extrusion
}

\author{
Lijun Wang \\ North Carolina Agricultural \& Technical State University, Iwang@ncat.edu \\ Girish M. Ganjyal \\ University of Nebraska-Lincoln, girish.ganjyal@mgpingredients.com \\ David D. Jones \\ University of Nebraska-Lincoln, david.jones@unl.edu \\ Curtis L. Weller \\ University of Nebraska-Lincoln, cweller1@unl.edu \\ Milford Hanna \\ University of Nebraska-Lincoln, mhanna1@unl.edu
}

Follow this and additional works at: https://digitalcommons.unl.edu/biosysengfacpub

Part of the Biological Engineering Commons

Wang, Lijun; Ganjyal, Girish M.; Jones, David D.; Weller, Curtis L.; and Hanna, Milford, "Modeling of Bubble Growth Dynamics and Nonisothermal Expansion in Starch-Based Foams During Extrusion" (2005). Biological Systems Engineering: Papers and Publications. 183.

https://digitalcommons.unl.edu/biosysengfacpub/183

This Article is brought to you for free and open access by the Biological Systems Engineering at DigitalCommons@University of Nebraska - Lincoln. It has been accepted for inclusion in Biological Systems Engineering: Papers and Publications by an authorized administrator of DigitalCommons@University of Nebraska Lincoln. 
Published in Advances in Polymer Technology 24:1 (2005), pp. 29-45; doi: 10.1002/adv.20030

Copyright (c) 2005 Wiley Periodicals, Inc. Used by permission.

http://www.interscience.wiley.com

Submitted September 22, 2003

\title{
Modeling of Bubble Growth Dynamics and Nonisothermal Expansion in Starch-Based Foams During Extrusion
}

\author{
Lijun Wang, Girish M. Ganjyal, David D. Jones, \\ Curtis L. Weller, and Milford A. Hanna \\ Industrial Agricultural Products Center, Department of Biological Systems Engineering, \\ University of Nebraska-Lincoln, Lincoln, NE 68583-0730, USA \\ Corresponding author - Lijun Wang; e-mail: 1wang5@unl.edu
}

\begin{abstract}
A mathematical model was developed to describe expansion phenomena in starch-based foams during extrusion. The model was divided into three parts to describe the microbubble growth dynamics, to couple bubble growth with extrudate expansion, and to describe the macrotransport phenomena in the extrudate, respectively. The differential equations involved in the model were solved by finite element schemes. For validating the model, the predicted radius, density, and residual moisture of final extrudate were compared with experimental data. Standard deviations between the predicted and experimental radius, density, and residual moisture of final extrudates were $16.7 \%, 11.2 \%$, and $39.3 \%$, respectively. The model was used to predict the profiles of downstream velocity, expansion ratio, moisture content, and temperature of extrudate during expansion.
\end{abstract}

Keywords: biodegradable, bubble growth, computer modeling, foam extrusion, swelling 


\section{Introduction}

$S_{\text {a }}^{\text {tard }}$ tarch-based materials are low-cost biopolymers and are obtained from renewable agricultural resources. Starch has been regarded as one of most promising raw materials to produce biodegradable thermoplastics. ${ }^{1-6}$ Starch-based foam is a lightweight biodegradable thermoplastic material, which can be used in packaging. ${ }^{7,} 8$ Extrusion is able to produce starch-based foam continuously. Expansion of extrudates is one of the most important phenomena of foam extrusion processing, resulting in a product with a cellular foam structure. ${ }^{9,10}$ During extrusion of starch-based foams, water can act both as a plasticizer for melting and as a blowing agent for expansion. When the melt passes out of an extruder through a die channel, it undergoes a thermodynamic instability caused by sudden pressure drop. This thermodynamic instability causes millions of nuclei of water vapor bubbles to be formed. ${ }^{11,} 12$ The bubbles grow in size as additional water vapor diffuses into the nuclei. As the melt exits from the nozzle, forming the extrudate, thermal expansion of water vapor pressure in the bubbles and water vapor diffusion into the bubbles cause further expansion before the final structure of the extrudate is set. The bubble growth within the extrudate is driven by the pressure difference across the shell of the bubbles and is opposed by viscoelastic stresses and surface tension in the bubble shell. ${ }^{10-16}$ Furthermore, when the melt emerges from the die channel, the viscous effects of the viscoelastic melt also cause die swell, increasing the diameter of the extrudate. ${ }^{17-19}$ Therefore, both bubble growth and die swell contribute to the expansion mechanism of starch-based foams.

Important parameters that affect the final dimension and qualities of extrudate are the die geometry, materials properties, and processing environment. ${ }^{9,}, 20$ It is desirable to be able to identify and quantify those parameters that would generate an extrudate with high expansion ratio and quality. Mathematical modeling and computer simulation have been used to investigate bubble growth and extrudate expansion during foam extrusion. Yang and Yeh ${ }^{13}$ developed a set of equations for describing the bubble growth in both Newtonian and non- Newtonian fluids. Street et al. ${ }^{14}$ further described the expansion of bubbles in finite spherical domains of a power-law fluid with various properties. Fan et al. ${ }^{15}$ presented a simplified theoretical model for single bubble growth and shrinkage in starch melt with various rheology and transport properties. Schwartzberg et al. ${ }^{16}$ took into account effects of flow yield stress, elastic stress, bubble ruptures, and coalescence in their model of bubble growth for analyzing popcorn expansion. Alavi et al. ${ }^{11,} 12$ recently developed a model including the effects of bulk diffusion and heat transfer through the extrudate on the bubble growth. However, we have found no publications on simultaneous analysis of bubble growth, die swell, and the resulting extrudate expansion.

The objective of this research was to mathematically characterize bubble growth at a microscopic level and extrudate expansion at a macroscopic level during the extrusion process of starch-based foams. The model was used to investigate the underlying mechanisms of extrudate expansion and to predict the profiles of downstream velocity, expansion ratio, moisture content, and temperature of extrudate during expansion.

\section{Mathematical Model}

\section{Description of Extrudate Expansion}

There are a large number of uniformly distributed bubble nuclei in a starch melt. ${ }^{21}$ For analysis, the porous starch melt was assumed to be formed by many small spherical domains as shown in Figure 1a. Each domain includes an inner bubble and melt shell. As shown in Figure 1b, the pressure inside each bubble nucleus continues to cause expansion as the confined forces outside of the domain drop. When the bubble expands, the domain expands. The bubble shell becomes thinner and thinner. Due to the difference of local environment, variation of domain size occurs during expansion. When the bubble shell becomes very thin, some bubbles rupture. Therefore, three things occur at the microlevel: (1) nucleation of bubbles as saturated moisture in the starch melt undergoes a pressure drop, (2) expansion of each bubble by a net driving force acting on the bubble shell, and (3) diffusion of water vapor from the starch matrix into the bubble.

Upon emergence of an extrudate from a die, the extrudate becomes a free-surface flow and die swell occurs due to the viscous effects of the extrudate. Therefore, the expansion of each bubble domain and the die swell of the extrudate contribute to the expansion mechanism of foams as a whole. The die geom- 


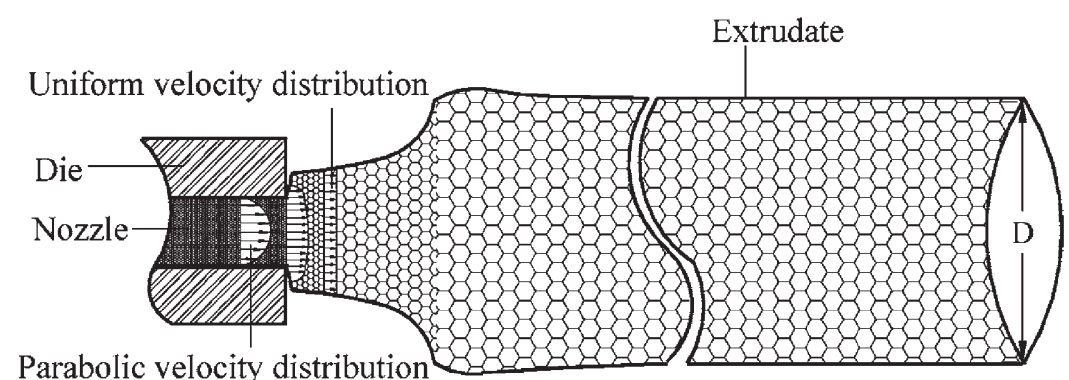

(a) Expansion of extrudate.
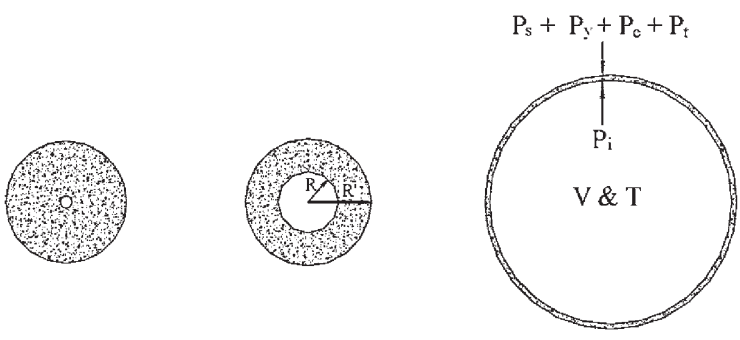

(b) Cross-section of bubble growth.

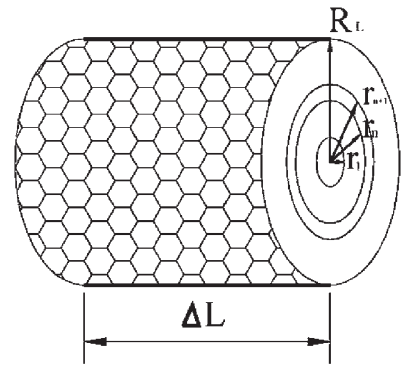

(c) Discretization of extrudate section.

Figure 1. Visualization of bubble growth and extrudate expansion during biofoam extrusion.

etry, properties of starch melt, and processing variables such as die temperature, moisture content, and product output affect the expansion of bubble domains. The expansion of an extrudate is thus completed at two conjunction levels: the microlevel of bubble growth and the macrolevel of transport phenomena in the extrudate. At the macrolevel, there occurs (1) viscoelastic flow of the extrudate, (2) heat transfer, and (3) bulk diffusion of moisture through the extrudate.

\section{Microbubble Growth Dynamics}

\section{Nucleation of Bubbles}

When starch melt, saturated with moisture, exits the die channel, there occurs a sudden pressure drop, resulting in a thermodynamic instability in the melt.
This instability causes many nuclei to be formed. $\mathrm{Nu}-$ cleation was assumed to be homogeneous and instantaneous in the extrudate. Nucleation can be characterized by the initial porosity, $\varphi_{0}$, of extrudate and the bubble number density, $N_{\mathrm{b}}$ (the number of bubbles formed per unit mass of the solid starch melt). The initial porosity of extrudate and nucleation density were input parameters in the model. Selection of those two parameters will be discussed in the section on model validation later on.

If the bubble density was $N_{\mathrm{b}}$, the mass of starch melt interacting with each bubble should be $(1+$ $\left.X_{\mathrm{w} 0}\right) / N_{\mathrm{b}}$. The initial average radius of bubbles was thus calculated as

$$
R_{0}=\left(\frac{3}{4 \pi} \frac{\left(1+X_{\mathrm{w} 0}\right)}{N_{\mathrm{b}} \rho_{\mathrm{s}}} \frac{\varphi_{0}}{1-\varphi_{0}}\right)^{1 / 3}
$$


The initial radius of each domain, including a bubble and a melt shell, was determined as

$$
R_{0}^{\prime}=\left(R_{0}^{3}+\frac{3}{4 \pi} \frac{\left(1+X_{\mathrm{w} 0}\right)}{N_{\mathrm{b}} \rho^{\mathrm{s}}}\right)^{1 / 3}
$$

\section{Bubble Growth Kinetics}

The expansion rate depends on the pressure difference between the inside and outside of a bubble and the rheological properties of starch melt. Bubble growth was analyzed in terms of a spherical pore in a spherical starch-based domain as shown in Figure $1 b$. The pressure difference can be expressed as

$$
\Delta P=P_{\mathrm{i}}-\left(P_{\mathrm{s}}+P_{\mathrm{t}}+P_{\mathrm{e}}+P_{\mathrm{y}}\right)
$$

where $P_{\mathrm{i}}$, is the pressure inside of a bubble, $P_{\mathrm{y}}$ is the reduction of pressure difference due to yield stress; $P_{\mathrm{e}}$ is the elastic stress; and $P_{\mathrm{t}}$ is the surface tension (Table I). The pressure outside of a bubble domain, $P_{\mathrm{s}^{\prime}}$ is equal to the atmospheric pressure after the extrudate exits the die.

Starch melt was assumed to be a pseudoplastic power-law fluid. ${ }^{22}$ The effective viscosity of a pseudoplastic power-law fluid can be expressed as

$$
\eta=K(\gamma)^{n-1}
$$

The expansion of a bubble in a power-law fluid of melt due to the pressure difference was described by Yang and Yeh, ${ }^{13}$ Street et al. ${ }^{14}$ and Schwartzberg et al. ${ }^{16}$ as

$$
\Delta P=\frac{4(2 \sqrt{3})^{n-1}}{n}\left(\frac{\dot{R}}{R}\right)^{n}\left[\xi+K_{\mathrm{bs}}-K_{\mathrm{d}^{\prime} \mathrm{s}}\left(\frac{R}{R^{\prime}}\right)^{3 n}\right]
$$

In Equation (5), $K_{\mathrm{bs}}$ and $K_{\mathrm{d} \text { 's }}$ were the values of $K$ in Equation (4) at the bubble surface and at the outer surface of a domain. $\xi$ accounted for variations of $K$ along the bubble surface to the outer surface of a domain. $\dot{R}$ was the expansion rate of bubble radius $(\dot{R}=$ $\mathrm{d} R / \mathrm{d} t)$.

In order to calculate the expansion rate of bubble radius, Equation (5) was rewritten as

$$
\dot{R}=\frac{\Delta R}{\Delta t}=R\left[\frac{\Delta P}{\frac{4(2 \sqrt{3})^{n-1}\left[\xi+K_{\mathrm{bs}}-K_{\mathrm{d}^{\prime} \mathrm{s}}\left(R / R^{\prime}\right)^{3 n}\right]}{n}}\right]^{1 / n}
$$

At a given time, the bubble radius, domain radius, and thickness of bubble shell were respectively expressed as

$$
\begin{aligned}
& R_{t+\Delta t}=R_{t}+\dot{R} \Delta t \\
& R_{t+\Delta t}^{\prime}=\left(R_{t+\Delta t}^{3}+\frac{3}{4 \pi} \frac{\left(1+X_{\mathrm{w}, \mathrm{d}^{\prime}, \text { aver }}\right)}{N_{\mathrm{b}} \rho_{\mathrm{s}}}\right)^{1 / 3} \\
& W_{t+\Delta t}=R_{t+\Delta t}^{\prime}-R_{t+\Delta t}
\end{aligned}
$$

\section{Diffusion of Water Vapor from the Starch Matrix into the Bubble}

Water vapor diffuses through the shell of a bubble into the bubble. The governing equation of the diffusion was

$$
\frac{\partial X_{\mathrm{w}, \mathrm{d}^{\prime}}}{\partial t}=\frac{1}{r^{2}} \frac{1}{\partial r}\left(r^{2} D_{\mathrm{w}, \mathrm{d}^{\prime}} \frac{\partial \mathrm{X}_{\mathrm{w}, \mathrm{d}^{\prime}}}{\partial r}\right)
$$

The initial condition of the above equation was given by

$$
\left.X_{\mathrm{w}, \mathrm{d}^{\prime}}\right|_{t=0}=X_{\mathrm{w} 0}
$$

The boundary conditions of Equation (10) were given by

$$
\begin{aligned}
\left.D_{\mathrm{w}, \mathrm{d}^{\prime}}\left(\frac{\partial \mathrm{X}_{\mathrm{w}, \mathrm{d}^{\prime}}}{\partial r}\right)\right|_{r=R} & =\frac{\dot{m}_{\mathrm{v}, \mathrm{c}}}{\rho^{\mathrm{s}}} \frac{1}{4 \pi R^{2}} \text { and }\left.\mathrm{X}_{\mathrm{w}, \mathrm{d}^{\prime}}\right|_{r=R^{\prime}} \\
& =X_{\mathrm{w}, \mathrm{d}^{\prime} \mathrm{s}}
\end{aligned}
$$

The mass cumulative rate of water vapor in a bubble was determined by

$$
\dot{m}_{\mathrm{v}, \mathrm{c}}=\frac{\Delta m_{\mathrm{v}, \mathrm{c}}}{\Delta t}=\frac{4 \pi R^{2}}{3 v \Delta t}\left[3(\Delta R)-a(\Delta T)+\beta\left(\Delta X^{\mathrm{w}, \mathrm{bs}}\right)\right]
$$

where

$$
\begin{aligned}
& a=\frac{G R}{P v}\left[1-T \frac{\mathrm{d}\left(\ln P^{*}\right)}{\mathrm{d} T}-\frac{T}{a_{\mathrm{w}}} \frac{\partial a_{\mathrm{w}}}{\partial T}\right] \\
& \beta=\frac{G R T}{P v a_{\mathrm{w}}} \frac{\partial a_{\mathrm{w}}}{\partial X_{\mathrm{w}, \mathrm{bs}}}
\end{aligned}
$$

\section{Coupled Bubble Growth with Extrudate Expansion}

An extrudate is built by a large number of small domains with a bubble inside of each domain. In order to couple the bubble growth with extrudate expansion, a piece of extrudate, which was generated at 
Table I. Equations for Calculating Physical Properties

\begin{tabular}{|c|c|c|}
\hline Property & Correlations or Values & References \\
\hline $\begin{array}{l}P_{i}(\mathrm{kPa}) \\
P_{\mathrm{y}}(\mathrm{kPa})\end{array}$ & $\begin{array}{l}P_{i}=a_{\mathrm{w}} P^{*}, P^{*}=1002.2 \exp [9.43699-3867.44 /(T-43.37)] \\
P_{\mathrm{Y}}= \pm 3.464 \tau_{0}\left[1 / 3+\ln \left(R^{\prime} / R\right)\right](+: \text { expansion, }-: \text { shrinkage }) \\
\tau_{0}=\tau_{r} \exp [0.013(298.15-T)]\left(X_{\mathrm{w}} \geq 0.14\right) \\
\tau_{0}=\tau_{r} \exp [0.013(298.15-T)] \exp \left[73\left(0.14-X_{\mathrm{w}}\right)\right]\left(X_{\mathrm{w}}<0.14\right), \tau_{r}=2 \mathrm{kPa}\end{array}$ & $\begin{array}{c}{[16]} \\
{[16,23]}\end{array}$ \\
\hline$P_{\mathrm{e}}(\mathrm{kPa})$ & $\begin{array}{l}P_{\mathrm{e}}=E\left[\frac{5}{2}-\frac{2 R_{0}}{R}-\frac{1}{2}\left(\frac{R_{0}}{R}\right)^{4}\right]\left(\frac{R^{\prime 3}-R^{3}}{R^{\prime 3}+2 R^{3}}\right) \\
E=E_{\mathrm{R}} \exp [0.013(298.15-T)]\left(X_{\mathrm{w}} \geq 0.14\right) \\
E=E_{\mathrm{R}} \exp [0.013(298.15-T)] \exp \left[73\left(0.14-X_{\mathrm{w}}\right)\right]\left(X_{\mathrm{w}}<0.14\right), E_{\mathrm{r}}=10 \mathrm{kPa} \\
P_{t}=2 \sigma / R(\sigma=0.05 \mathrm{~N} / \mathrm{m})\end{array}$ & {$[16,23]$} \\
\hline$K$ & Melt in die: $K=106.25 \exp \left[\frac{2451}{T}-4.63 X_{\mathrm{w}}\right], n=0.37$ & [27] \\
\hline & $\begin{array}{l}\text { Extrudate: } K=0.672 \exp \left[\frac{4960}{T}-12.1 \frac{X_{\mathrm{w}}}{1+X_{\mathrm{w}}}\right], n=0.4 \\
\text { Variation of } K \text { in extrudate: } \xi=\int_{R}^{R^{\prime}} \frac{\partial K}{\partial r}\left(\frac{R}{r}\right)^{3 n} \mathrm{~d} r\end{array}$ & {$[12,16]$} \\
\hline$\rho\left(\mathrm{kg} / \mathrm{m}^{3}\right)$ & $\begin{array}{l}\rho_{\mathrm{w}}=1000 \\
\rho_{\mathrm{m}}=1200 \\
\rho_{\mathrm{s}}=1500\end{array}$ & $\begin{array}{l}{[25]} \\
{[27]} \\
{[33]}\end{array}$ \\
\hline$k(\mathrm{~W} / \mathrm{m} \mathrm{K})$ & $\begin{array}{l}K_{\mathrm{e}}=\phi_{\mathrm{v}} K_{\mathrm{v}}+\left(1-\phi_{\mathrm{v}}\right) K_{\mathrm{m}}, \phi_{\mathrm{v}}=1-\rho_{\mathrm{e}} / \rho_{\mathrm{m}} \\
K_{\mathrm{m}}=\frac{\left(1-\phi_{\mathrm{w}}\right)}{K_{\mathrm{s}}}+\frac{\phi_{\mathrm{w}}}{K_{\mathrm{w}}}, \phi_{\mathrm{w}}=\rho_{\mathrm{s}} X_{\mathrm{w}} /\left(\rho_{\mathrm{w}}+\rho_{\mathrm{s}} X_{\mathrm{w}}\right)\end{array}$ & [33] \\
\hline & $\begin{array}{l}K_{s}=0.322+0.41 \times 10^{-2} T \\
K_{\mathrm{w}}=0.571+1.76 \times 10^{-3} T-6.7 \times 10^{-6} T^{2} \\
K_{\mathrm{v}}=0.00324+5.31 \times 10^{-4} T\end{array}$ & $\begin{array}{l}{[33]} \\
{[25]} \\
{[25]}\end{array}$ \\
\hline$c_{p}(\mathrm{~J} / \mathrm{kg} \mathrm{K})$ & $\begin{array}{l}c=1.291+2.321 X_{\mathrm{w}} \\
\Delta c_{\mathrm{p} 1}=1.94 \text { and } \Delta c_{\mathrm{p} 2}=0.425\end{array}$ & {$[25]$} \\
\hline$T_{\mathrm{g}}(\mathrm{K})$ & $T_{\mathrm{g} 1}=134$ and $T_{\mathrm{g} 2}=500$ & {$[26]$} \\
\hline$D_{\mathrm{w}}\left(\mathrm{m}^{2} / \mathrm{s}\right)$ & $\begin{array}{l}\text { In cell domain: } D_{\mathrm{w}, \mathrm{d}^{\prime}}=1.35 \times 10^{-8} \exp \left[\frac{-21.61(548-T)\left(1.194+3.68 X_{\mathrm{w}}\right)}{T\left(1+18.98 X_{\mathrm{w}}\right)}\right] \\
\text { In porous extrudate: } D_{\mathrm{w}, \mathrm{e}}=\left(1-\varepsilon_{\mathrm{v}}\right) D_{\mathrm{w}, \mathrm{d}^{\prime}}, \varepsilon_{\mathrm{v}}=1-\rho_{\mathrm{e}} / \rho_{\mathrm{s}}\end{array}$ & {$[11,16,34]$} \\
\hline$\lambda(\mathrm{kj} / \mathrm{kg})$ & $\lambda=2250$ & [25] \\
\hline$v\left(\mathrm{~kg} / \mathrm{m}^{3}\right)$ & $v=\frac{G T}{P}-0.0167$, where $G=0.4561\left(\mathrm{~m}^{3} \mathrm{kPa} /(\mathrm{kg} \mathrm{K})\right.$ & [16] \\
\hline$a_{\mathrm{w}}$ & $\begin{array}{l}a_{\mathrm{w}}=B X_{\mathrm{w}, \mathrm{bs}}+\frac{C X_{\mathrm{w}, \mathrm{bs}}}{F+X_{\mathrm{w}, \mathrm{bs}}}\left(B=-0.5362-0.001394 T+\frac{2.0474(468.9-T)}{477.42-T_{\mathrm{K}}},\right. \\
\left.C=0.2479+0.001216 T \text { and } F=0.002004+0.3165 \times 10^{-5} T\right)\end{array}$ & [16] \\
\hline $\begin{array}{l}h_{\mathrm{t}}\left(\mathrm{W}\left(\mathrm{m}^{2} \mathrm{~K}\right)\right) \\
h_{\mathrm{m}}(1 / \mathrm{m}) \\
h_{\mathrm{e}}\left(\mathrm{kg}\left(\mathrm{Pa} \mathrm{m} \mathrm{m}^{2} \mathrm{~s}\right)\right)\end{array}$ & $\begin{array}{l}h_{\mathrm{t}}=15 \\
h_{\mathrm{m}}=1 \times 10^{-5} \\
h_{\mathrm{e}}=8.4 \times 10^{-7}(T \geq 373.15 \mathrm{~K}) \text { and } h_{\mathrm{e}}=3.5 \times 10^{-8}(T<373.15 \mathrm{~K})\end{array}$ & $\begin{array}{l}{[12]} \\
{[12]} \\
{[24]}\end{array}$ \\
\hline
\end{tabular}

a $\Delta t$ time step was chosen as shown in Figure 1c. The length of generated extrudate was calculated by

$$
\Delta L=u_{\text {aver }} \Delta t
$$

where $u_{\text {aver }}$ was the average velocity of extrudate.
The mass flow rate of dry solids in the melt was given by

$$
\dot{m}_{\mathrm{s}}=\dot{m}_{t} /\left(1+X_{\mathrm{w} 0}\right)
$$

The cylindrical extrudate was discretized into $N_{\mathrm{e}}$ concentric layers with equal weights of solid melt for 
each layer as shown in Figure 1c. The mass flow rate of solid melt in each layer was then given by

$$
\dot{m}_{\mathrm{s}, i}=\dot{m}_{\mathrm{s}} / N_{\mathrm{e}}
$$

The weight of each layer was then

$$
m_{\mathrm{s}, i}=\dot{m}_{\mathrm{s}, i} \Delta t
$$

The total number of bubbles in each layer of the extrudate piece was given by

$$
N_{\mathrm{b}, i}=m_{\mathrm{s}, i} N_{\mathrm{b}}
$$

If the stress in a bubble shell, $S_{w^{\prime}}$ exceeds the tensile failure stress, $S_{f}$, the bubble shell ruptures. For a spherical domain, the shell stress was determined as

$$
\begin{aligned}
& S_{\mathrm{w}, i}=\frac{\Delta P_{i} R_{i}^{2}}{W_{i}^{2}+2 W_{i} R_{i}} \quad\left(W_{i} / R_{i} \geq 0.1\right) \\
& S_{\mathrm{w}, i}=\frac{\Delta P_{i} R_{i}}{2 W_{i}} \quad\left(W_{i} / R_{i}<0.1\right)
\end{aligned}
$$

where $\Delta P_{i}, R_{i}$, and $W_{i}$ were pressure difference, the average radius, and shell thickness of bubbles in the $i$-th layer of the extrudate, respectively.

The failure stress was given by Cummings and Okos ${ }^{23}$ and Schwartzberg et al. ${ }^{16}$ as

$$
\begin{aligned}
& S_{\mathrm{f}, i}=S_{\mathrm{m}} \exp \left[a_{\mathrm{s}}\left(T_{0}-T_{i}\right)\right],\left(X_{\mathrm{w}, \mathrm{d}^{\prime}, \text { aver }, \mathrm{i}} \geq 0.14\right) \\
& S_{\mathrm{f}, i}=S_{\mathrm{m}} \exp \left[a_{\mathrm{s}}\left(T_{0}-T_{i}\right)\right] \exp \left[\beta_{\mathrm{s}}\left(X^{0}-X_{\mathrm{w}, \mathrm{d}^{\prime}, \text { aver }, \mathrm{i}}\right)\right] \\
&\left(X_{\mathrm{w}, \mathrm{d}^{\prime}, \text { aver }, \mathrm{i}}<0.14\right)
\end{aligned}
$$

where $T_{0}$ and $X_{0}$ are the reference temperature and reference moisture, respectively $\left(T_{0}=298.15 \mathrm{~K}\right.$ and $X_{0}$ $=0.14$, dry basis), $a_{\mathrm{s}}$ and $\beta_{\mathrm{s}}$ are the temperature and moisture shift factors, respectively $\left(a_{\mathrm{s}}=0.013\right.$ and $\beta_{\mathrm{s}}$ $=73) ; S_{\mathrm{m}}$ is a constant $\left(S_{\mathrm{m}}=1,000 \mathrm{kPa}\right) ; T_{i}$ is the shell temperature of bubbles; and $X_{\mathrm{w}, \mathrm{d}}$,aver,i is the average moisture of bubble shell in the $i$-th layer of the extrudate.

Because of variations in initial bubble radius and melt properties, the bubbles may not rupture simultaneously when the shell stress equals the failure stress, based on the average bubble radius and melt properties. Schwartzberg et al. ${ }^{16}$ introduced a modified normal distribution function to determine the increasing number of open bubbles in the $i$-th layer of the extrudate at time step, $t$, which was expressed as

$$
\Delta f_{\mathrm{o}, \mathrm{i}, \mathrm{t}}=\frac{\Delta \mathrm{Z}_{i}}{\sqrt{2 \pi}} \exp \left[\frac{-Z_{i}^{2}}{\psi}\right]
$$

where $Z_{i}=\left(S_{\mathrm{W}, i}-S_{\mathrm{f}, i}\right) / 2 S_{\mathrm{f}, i}$ and $\psi$ determines the spread of $\Delta f_{\mathrm{o}, \mathrm{i}, \mathrm{t}^{\prime}} \psi=2.5$.

The number fraction of bubbles that are open, $f_{\mathrm{o}^{\prime}}$ varies between 0 and 1 . The number fraction of open bubbles at time step, $n+1$, was thus calculated by

$$
f_{\mathrm{o}, n+1}=f_{\mathrm{o}, n}+\Delta f_{\mathrm{o}, n+1}
$$

If a bubble in a layer of extrudate is closed, the bubble has the ability to expand. Otherwise, if a bubble is open, the bubble loses its ability to expand and the domain radius will remain constant. The volume of a layer at the $(n+1)$-th time step is the sum of the closed domain volume and open domain volume, which was calculated by

$$
\begin{aligned}
V_{i}=\frac{4}{3} \pi R_{i, n+1}^{\prime 3}\left(1-f_{\mathrm{o}, i, n+1}\right) N_{b, i} \\
+\sum_{t=1}^{n+1} \frac{4}{3} \pi R_{\mathrm{o}, i, t}^{\prime 3} \Delta f_{\mathrm{o}, i, t} N_{\mathrm{b}, i}
\end{aligned}
$$

In Equation (27), the first and second terms of the righthand side were used to calculate the total volume of closed bubble domains and the total volume of opened bubble domains for each layer of the extrudate, respectively.

The distance of the $i$-th layer from the axial axes of the extrudate was determined by

$$
r_{i}=\left(\frac{V_{i-1}}{\pi \Delta L}+r_{i-1}^{2}\right)^{1 / 2}
$$

\section{Macro-Transport Phenomena in the Extrudate}

\section{Viscoelastic Flow of the Extrudate}

Melt flow in the die was assumed to be non- Newtonian fluid. Because the die was symmetrical about its central axis, only half of the axial cross-section was chosen for analysis. The governing equation of momentum in the downstream direction was written as

$$
\rho\left(\frac{\partial u}{\partial t}+u \frac{\partial u}{\partial z}\right)=-\frac{\partial P_{\mathrm{s}}}{\partial z}+\frac{1}{r} \frac{\partial}{\partial r}\left(r \eta \frac{\partial u}{\partial r}\right)
$$

The initial condition of Equation (29) was given by

$$
u_{t=0}=u_{0}
$$


The boundary conditions of the above equation were given by

$$
\begin{aligned}
& \left.\frac{\partial u}{\partial r}\right|_{r=0}=0 \\
& \left.u\right|_{r=R}=0 \text { (for die flow) and } \sigma_{r=R}^{\prime}=0 \\
& \quad \text { (for free-surface flow) }
\end{aligned}
$$

The viscoelastic flow of extrudate can be divided into two parts: the upstream region being inside of the die and the downstream region being outside of the die. For the viscoelastic melt in the die, there exists drag flow and pressure flow. Drag flow is caused by the viscous stress, and pressure flow is dependent on the pressure gradient from the die entrance to the die exit. In order to solve the momentum equation for the upstream region, an integral-type continuity equation was used to iteratively determine the pressure gradient in Equation (29). The continuity equation was written as

$$
\int_{0}^{R}(2 \pi r u \cdot \rho) \mathrm{d} r=\dot{m}_{t}
$$

Upon emergence of an extrudate from a die, the extrudate becomes a free-surface flow. Meanwhile, the extrudate exhibits an increase in the cross-section due to the viscous effects and the bubble growth inside of the extrudate. In this case, in order to determine the dimension of the swollen extrudate, the momentum equations of free-surface extrudate flow (Equations (29)-(32)) were solved together with the equations for coupling the microlevel bubble growth with macrolevel extrudate expansion (Equations (16)-(28)).

\section{Bulk Diffusion of Water in the Extrudate}

During expansion, moisture loss occurs in three ways: (1) by evaporation in closed bubbles for expanding the bubbles, (2) by evaporation on the hot wall surface of open cells and then released to the ambient, and (3) by diffusion to the outer surface of the extrudate in a liquid form and then released to the atmosphere as vapor. The general governing equation of moisture diffusion through the extrudate, in axisymmetric coordinates, can be written as

$$
\frac{\partial X_{\mathrm{w}, \mathrm{e}}}{\partial t}=\frac{1}{r} \frac{\partial}{\partial r}\left(r D_{\mathrm{w}, \mathrm{e}} \frac{\partial X_{\mathrm{w}, \mathrm{e}}}{\partial r}\right)+\dot{X}_{\mathrm{v}, \mathrm{e}}
$$

The initial condition was given by

$$
\left.X_{\mathrm{w}, \mathrm{e}}\right|_{t=0}=X_{\mathrm{w} 0}
$$

The boundary conditions of Equation (34) were given by

$$
\begin{aligned}
\left.D_{\mathrm{w}, \mathrm{e}} \frac{\partial X_{\mathrm{w}, \mathrm{e}}}{\partial r}\right|_{r=0} & =0 \text { and }\left.D_{\mathrm{w}, \mathrm{e}} \frac{\partial X_{\mathrm{w}, \mathrm{e}}}{\partial r}\right|_{r=R_{\mathrm{e}}} \\
& =h_{\mathrm{m}}\left(X_{\mathrm{w}, \mathrm{es}}-X_{\mathrm{w}, \mathrm{a}}\right)
\end{aligned}
$$

In the above equation, the moisture loss rate due to water evaporation into closed bubbles and on the hot surface wall of open bubbles was considered to be the inner vapor generation rate. The inner vapor generation rate at the $(n+1)$-th time step was expressed as the ratio of the generation rate of vapor mass and the mass of dried solid extrudate, which was given by

$$
\dot{X}_{\mathrm{v}, \mathrm{e}}=\dot{m}_{\mathrm{v}, \mathrm{c}} N_{\mathrm{b}}\left(1-f_{\mathrm{o}, n+1}\right)+\sum_{t=1}^{n+1} \dot{m}_{\mathrm{v}, \mathrm{o}} N_{\mathrm{b}} \Delta f_{\mathrm{o}, t}
$$

In the above equation, the mass cumulative rate of water vapor into closed bubbles, $\dot{m}_{\mathrm{v}, \mathrm{c}^{\prime}}$ was determined by Equation (13). The mass evaporation rate of water vapor on the wall of opened bubbles, $\dot{m}_{\mathrm{v}, \mathrm{o}^{\prime}}$ was calculated as

$$
\dot{m}_{\mathrm{v}, \mathrm{o}}=h_{\mathrm{e}} \cdot\left(4 \pi R_{\mathrm{o}}^{2}\right) \cdot\left(a_{\mathrm{w}} P_{\mathrm{sat}}-P_{\mathrm{s}}\right)
$$

where $h_{\mathrm{e}}$ was the evaporation coefficient of water, the experimental result gave $h_{\mathrm{e}}=8.4 \times 10^{-7}\left(\mathrm{~kg} /\left(\mathrm{Pa} \mathrm{m}^{2} \mathrm{~s}\right)\right.$ for the wall temperature above $100^{\circ} \mathrm{C}$ (boiling) and $h_{\mathrm{e}}$ $=3.5 \times 10^{-8}\left(\mathrm{~kg} /\left(\mathrm{Pa} \mathrm{m}^{2} \mathrm{~s}\right)\right)$ for the wall temperature below $100^{\circ} \mathrm{C}$ (evaporation). ${ }^{24} P_{\text {sat }}$ was the saturation pressure of water at the temperature of the bubble wall. $P_{\mathrm{s}}$ was the ambient pressure for boiling and partial vapor pressure in the ambient for evaporation.

At the macrolevel, moisture diffuses to the extrudate surface and evaporates to the ambient environment. The evaporation rate on the extrudate surface was the difference of the total moisture loss and the water evaporation (boiling) in the bubbles, which was expressed as

$$
m^{\prime}{ }_{\mathrm{w}, \mathrm{es}}=\sum_{i=1}^{N_{\mathrm{e}}} \dot{m}_{\mathrm{s}, i}\left(X_{\mathrm{w}, \mathrm{e}}^{i, t}-X^{i, t}{ }_{\mathrm{w}, \mathrm{d}^{\prime}, \mathrm{aver}}\right)
$$

Because moisture diffuses through the extrudate, the moisture contents in a bubble shell also are reduced. The transient moisture contents in a shell, $X_{w, d^{\prime}, j^{\prime}}$, were reduced in the same proportion, $X_{\mathrm{w}, \mathrm{e}}^{i, t} / X_{\mathrm{w}, \mathrm{d}^{\prime}, \mathrm{aver}}^{i, \mathrm{w}^{\prime}}$, for the $i$-th layer in the extrudate. 


\section{Heat Transfer in the Extrudate}

When extrudate exits from the die, heat is transferred. At a macrolevel, the thermal behavior in the extrudate includes (1) inner heat generation due to water evaporation in bubbles and melt matrix solidification; (2) heat conduction through the extrudate body; and (3) heat release from the extrudate surface due to heat convection, radiation, and water evaporation on the surface. Heat transfer was thus modeled using Fourier's equation of heat conduction with inner heat generation source in an infinite cylindrical body, which was expressed as

$$
\rho c_{\mathrm{p}} \frac{\partial \mathrm{T}}{\partial t}=\frac{1}{r} \frac{\partial}{\partial r}\left(r k \frac{\partial T}{\partial r}\right)+\dot{q}
$$

At the beginning of expansion, the extrudate temperature was equivalent to the die temperature. The initial condition of Equation (40) was thus given by

$$
\left.T\right|_{t=0}=T_{\mathrm{d}}
$$

On the boundary of the extrudate, the heat is released through heat convection, radiation, and water evaporation. The boundary conditions were thus given by

$$
\begin{gathered}
\left.k \frac{\partial T}{\partial r}\right|_{r=0}=0 \text { and }\left.k \frac{\partial T}{\partial r}\right|_{r=R_{\mathrm{e}}}=h_{t}\left(T_{\mathrm{es}}-T_{\mathrm{a}}\right)+q_{\text {es }}^{\prime} \\
q_{\text {es }}^{\prime}=\lambda \frac{m_{\mathrm{w}, \mathrm{es}}^{\prime}}{A_{\mathrm{es}}}
\end{gathered}
$$

The inner vapor generation rate was expressed as the ratio of the heat generation rate due to evaporation and the volume of extrudate, which was given by

$$
\dot{q}=\lambda \frac{3 \dot{m}_{\mathrm{v}, \mathrm{c}}}{4 \pi R^{\prime 3}}\left(1-f_{\mathrm{o}, n+1}\right)+\lambda \sum_{t=1}^{n+1} \frac{3 \dot{m}_{\mathrm{v}, \mathrm{o}}}{4 \pi R_{\mathrm{o}}^{\prime 3}} \Delta f_{\mathrm{o}, t}
$$

The evaporation in bubble cells absorbs sensible heat from the melt matrix, cooling the matrix. Meanwhile, the melt solidification due to the temperature decrease, releases heat to the melt matrix, heating the matrix. During expansion, the latent heat of solidification is very small (on the order of $10 \mathrm{~kJ} / \mathrm{kg}$ ) compared to $2250 \mathrm{~kJ} / \mathrm{kg}$ for latent heat of vaporization of water. ${ }^{25}$ Although the mass ratio of melt matrix to moisture loss during expansion may be as high as 10, the ratio of total latent heat of melt solidification to water vaporization is less than 0.05 . Therefore, the latent heat of melt solidification was neglected in the model. The glass transition temperature of the corn starch extrudate was estimated by

$$
T_{\mathrm{g}}=\frac{M_{1} \Delta c_{\mathrm{p} 1} T_{\mathrm{g} 1}+M_{2} \Delta c_{\mathrm{p} 2} T_{\mathrm{g} 2}}{M_{1} \Delta c_{\mathrm{p} 1}+M_{2} \Delta c_{\mathrm{p} 2}}
$$

where $M_{1}$ and $M_{2}$ are mass fractions of moisture and solid starch, respectively. The constants are given in Table I. ${ }^{26}$

\section{Simulation Procedure}

A computer program was written to solve the model. The flow chart of the program is given in Figure 2. The program was divided into four parts: (1) input information, (2) bubble growth, (3) coupled bubble growth with extrudate expansion, and (4) transport phenomena in the extrudate, respectively. The stepwise calculations were as follows:

1. The simulation began with the input of die nozzle geometry including the diameter and length of the nozzle, mass flow rate of feed, density of the melt, initial moisture content, and initial melt temperature at the exit of the die, initial porosity, and bubble density.

2. The initial bubble radius, $R_{0^{\prime}}$ and domain radius, $R^{\prime}{ }_{0}$, were calculated by Equations (1) and (2), respectively. The initial moisture, $X_{\mathrm{w} 0}$, temperature, $T_{0}$, and pressure, $P_{\mathrm{s}}$ were the input parameters of the model.

3. Using the values of $R, R^{\prime}, X_{\mathrm{w}^{\prime}}, T$, and $P_{\mathrm{s}}$ at the current time step, the bubble radius, domain radius, and thickness of bubble wall at next time step were determined by Equations (3)-(9). The shell of the bubble was divided into 10 layers with equal mass of solid melt in each layer. The moisture distribution in the bubble shell was then calculated by Equations (10)-(15).

4. The extrudate was divided into 10 layers with equal mass of solid melt in each layer. The length of extrudate generated at a time step was calculated by Equation (16). The total number of cells in each layer was determined by Equations (17)(20). The wall stress of bubble cells was calculated by Equations (21) and (22), and the failure stress of bubble cells was calculated by Equations (23) and (24). The increasing number and number fraction of open cells at the $(n+1)$-th time step were determined by Equations (25) and (26), respectively. As the extrudate was divided into several layers during calculation, the volume of each extrudate layer was calculated by Equation (27). The coordinate of 


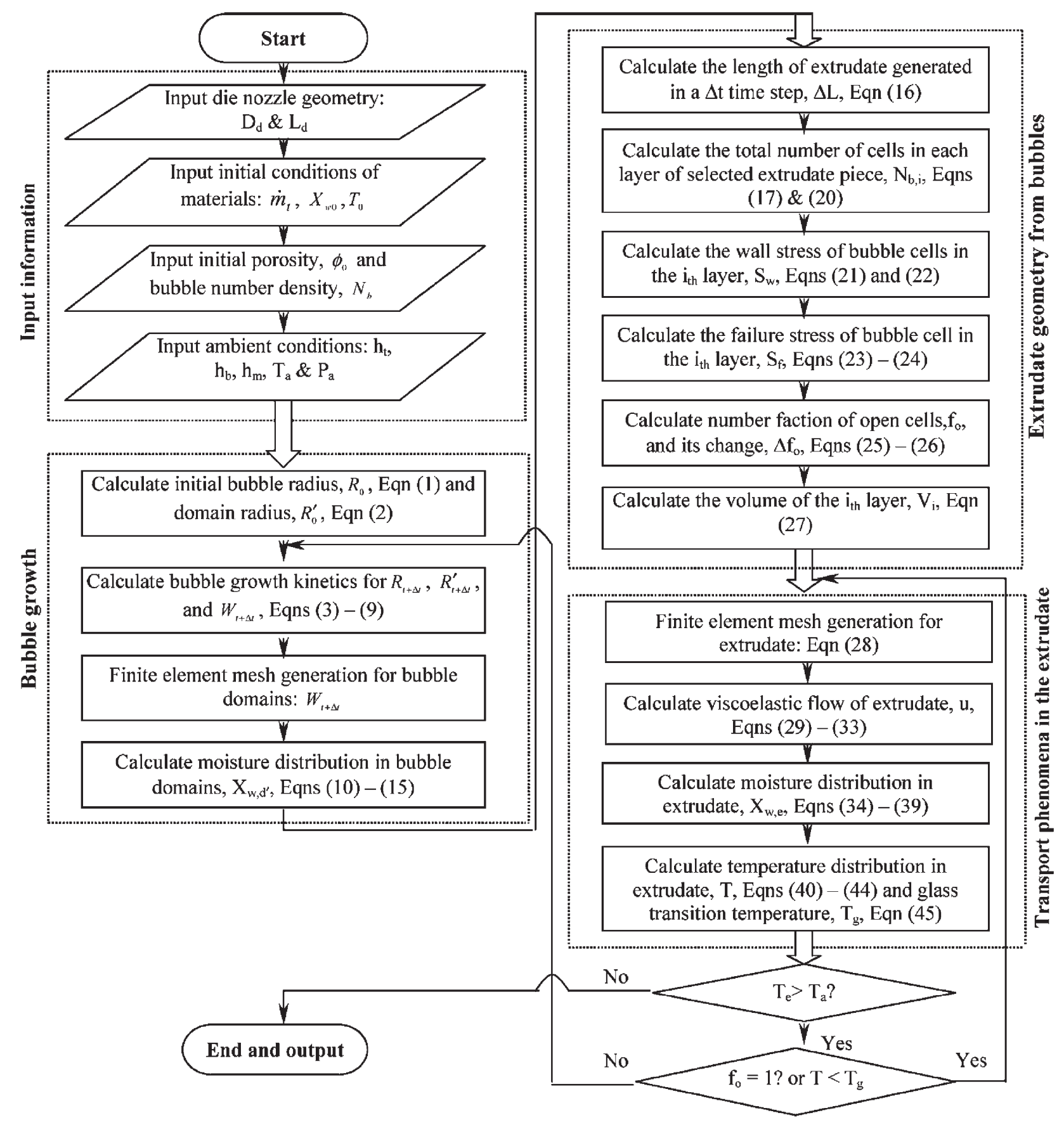

Figure 2. The flowchart of simulation program.

each layer in the extrudated was then determined by Equation (28).

5 . The velocity distribution in the extrudate was calculated by Equations (29)-(33). The moisture distribution in the extrudate was calculated by Equations (34)-(39). The moisture contents in a domain were reduced in the same proportion as the reduction of average moisture contents in the corresponding layer of the extrudate. The tempera- ture distribution in the extrudate was calculated by Equations (40)-(44). Finally, the glass transition temperature of the extrudate was determined by Equation (45).

If the temperature of extrudate was higher than the ambient temperature, the computation was continued by repeating the steps (3)-(5). Otherwise, the computation was terminated. 


\section{Results and Discussion}

\section{Model Validation}

In order to validate the model, predicted expansion ratio, density, and residual moisture for each of the final extrudates were compared with experimental data for different die nozzle diameters and processing conditions.

Normal corn starch (25\% amylose and 75\% amylopectin) purchased from National Starch and Chemical Co. (Bridgeport, NJ) was used in the experiments. The moisture content of the starch was adjusted to $20 \%$ (dry base) by blending with distilled water. The samples were sealed in plastic buckets and stored at $4^{\circ} \mathrm{C}$ for one day. Before extrusion, the samples were removed from cold storage and allowed to come to room temperature.

The starch was extruded in a counter rotating twin-screw laboratory extruder (model CTSE-V, C. W. Brabender, Inc., South Hackensack, NJ, USA). The conical screws had diameters decreasing from 42.5 to $27.5 \mathrm{~mm}$ along a length of $350 \mathrm{~mm}$ from the feed end to the exit end. Three die nozzles with different diameters were used. The detailed dimensions of the die nozzles are given in Table II. Rotational speeds were set at 120 or $140 \mathrm{rpm}$. Feed rates were $6.11 \mathrm{~kg} / \mathrm{h}$ for the rotational speed of $120 \mathrm{rpm}$ and $6.41 \mathrm{~kg} / \mathrm{h}$ for $140 \mathrm{rpm}$, respectively. Temperature at the feed zone of the extruder barrel was set at $50^{\circ} \mathrm{C}$, whereas the remaining zones and the die were set at $140^{\circ} \mathrm{C}$ and $125^{\circ} \mathrm{C}$, respectively. The extruder was controlled by a plasti-Corder (type FE 2000, C. W. Brabender, Inc.,
South Hackensack, NJ, USA). The barrel temperatures and the temperature of the product at the die were recorded using temperature probes (Omega Engineering Inc., Stamford, Conn., USA).

The moisture contents of feed materials and extrudates were measured by a moisture analyzer at the chamber temperature of $105^{\circ} \mathrm{C}$ (HG 53 moisture analyzer, Mettler-Toledo GmbH, Laboratory \& Weighing Technologies, Greifensee, Switzerland). The densities of extrudates were determined using a glass bead displacement method. Glass beads of $1 \mathrm{~mm}$ diameter were used as displacement media to determine the volume of an extrudate sample. The density was calculated by dividing the mass of a sample by the sample volume. Diameters of the extrudates were measured with a Vernier caliper (Sylvac, Fowler Tools and Instruments, Boston, USA). All measurements were done in triplicates.

The comparisons between predictions and experiments are shown in Table II. Each experimental value was an average of three readings. There was a reasonable agreement between the predictions and experimental data as shown in Table II. The standard deviations for radius, density, and residual moisture of final extrudates were $16.7 \%, 11.2 \%$, and $39.3 \%$, respectively.

The accuracy of the measurements was a possible reason for the variations between the predictions and experimental data. The input parameters and assumptions of the model may also contribute to the deviations between the predictions and experimental observations. The deviations due to the input parameters and assumptions of the model are discussed as follows.

Table II. Experimental and Predicted Radius and Density of Extrudate for Different Nozzle Geometries and Processing Conditions

\begin{tabular}{|c|c|c|c|c|c|c|c|c|c|c|}
\hline $\begin{array}{l}D, \\
(\mathrm{~mm})\end{array}$ & $\begin{array}{c}L \\
(\mathrm{~mm})\end{array}$ & $\begin{array}{c}\dot{m}_{t} \\
(\mathrm{~kg} / \mathrm{h})\end{array}$ & $\begin{array}{c}X_{\mathrm{w} 0} \% \\
\mathrm{db}\end{array}$ & $\begin{array}{c}T_{0} \\
\left({ }^{\circ} \mathrm{C}\right)\end{array}$ & $\begin{array}{l}\text { Predicted } \\
(\mathrm{mm})\end{array}$ & $\begin{array}{l}\text { Measured } \\
\quad(\mathrm{mm})\end{array}$ & $\begin{array}{l}\text { Predicted, } \\
\left(\mathrm{kg} / \mathrm{m}^{3}\right)\end{array}$ & $\begin{array}{l}\text { Measured, } \\
\left(\mathrm{kg} / \mathrm{m}^{3}\right)\end{array}$ & $\begin{array}{l}\text { Predicted, } \\
\text { (\%db) }\end{array}$ & $\begin{array}{l}\text { Measured, } \\
(\% \mathrm{db})\end{array}$ \\
\hline 3.00 & 14.6 & 6.11 & 20 & 127 & 10.56 & 9.28 & 277 & 335 & 12.85 & 8.40 \\
\hline 3.00 & 14.6 & 6.41 & 20 & 125 & 10.08 & 9.76 & 300 & 339 & 12.85 & 8.31 \\
\hline 4.00 & 14.6 & 6.41 & 20 & 127 & 13.40 & 11.45 & 295 & 316 & 12.49 & 10.31 \\
\hline 5.00 & 14.5 & 6.11 & 20 & 127 & 16.35 & 12.18 & 283 & 317 & 12.38 & 9.40 \\
\hline 5.00 & 14.5 & 6.41 & 20 & 129 & 14.90 & 12.01 & 340 & 306 & 12.11 & 9.18 \\
\hline
\end{tabular}


Among the three parameters of initial porosity, bubble number density, and initial bubble diameter, if two parameters are given, the third one can be calculated by Equation (1). The initial porosity, $\varphi_{0}$, was assumed to be $20 \%$ based on $\varphi_{0}=1-\rho_{\mathrm{m}} / \rho_{\mathrm{s}}$ at $\rho_{\mathrm{m}}=$ $1200 \mathrm{~kg} / \mathrm{m}^{3}$ and $\rho_{\mathrm{s}}=1500 \mathrm{~kg} / \mathrm{m}^{3} \cdot{ }^{27,} 28$ It was reported that the highest bubble density values for native amylopectin were in the order of the hundreds per gram of starch extrudate. ${ }^{21}$ In this paper, the bubble density was assumed to be 200 bubbles/g starch. However, the different pressure drop rates and the moisture contents of melt may have resulted in different bubble number densities and porosities.

A proper rheological correlation is important in the determination of die swell and bubble radius. Most correlations describe the rheological behavior in terms of a power law, which depends on temperature, moisture content, and shear rate and are well applicable to a high shear rate situation. ${ }^{22}$ However, when extrudate leaves the die, the shear rate will rapidly approach zero as the extrudate encounters freesurface flow. The mean shear rate in an extrudate die may be as high as 200-500 s ${ }^{-1}$, compared to $10^{-2}-5 \mathrm{~s}^{-1}$ during bubble growth. ${ }^{15}$ Selection of a suitable rheological correlation for low shear rate die swell and bubble growth is important for the accuracy of model predictions.

Water was both a plasticizer and a blowing agent for expansion during the extrusion of starch-based foam. Moisture content not only affects the rheological value of the melt matrix but also the diffusion rate of moisture through the bubble shell and evaporation rate on the bubble surface. During melting, the exact moisture content of melt at the exit of die nozzle may not be the same as the initial moisture of feed starch due to moisture loss. Neglecting moisture loss during melting may cause deviations between predictions and experiments.

The elastic modulus of melt surrounding a bubble, $E$, flow yield stress, $\tau_{0}$, and bubble shell failure stress, $S_{\mathrm{f}}$, were three important parameters in the model to determine the stresses on the bubble shell and to determine the bubble rupture. Cummings and Okos ${ }^{23}$ and Schwartzberg et al. ${ }^{16}$ used similarly formulated equations with different coefficients to describe how $E, \tau_{0}$, and $S_{\mathrm{f}}$ depended on the moisture, $X$, and temperature, $T$, of the bubble shell. Generally, (1) $E, \tau_{0}$ and $S_{\mathrm{f}}$ increase as $T$ decreases; (2) the effect of $X$ on $E$, $\tau_{0}$, and $S_{\mathrm{f}}$ are negligible when $X$ is larger than a critical value; and (3) $E, \tau_{0}$, and $S_{\mathrm{f}}$ increase as $X$ decreases when $X$ is below a critical value. In this paper, equa- tions similar to those of Cummings and $\mathrm{Okos}^{23}$ and Schwartzberg et al. ${ }^{16}$ were used to correlate the values of $E, \tau_{0}$, and $S_{\mathrm{f}}$. Quantitative description of elastic modulus, flow yield stress, and wall failure stress for different materials was still difficult which contributed to the deviations between predictions and experimental data in this research.

\section{Expansion Ratios of Extrudate}

The histories of overall, radial, and axial expansions of extrudate are shown in Figure 3. The overall expansion was expressed as a ratio of bulk density and extrudate solid density. The radial expansion was calculated by dividing the cross-sectional area of the extrudate by the cross-sectional area of the die nozzle. Axial expansion was calculated by dividing the overall expansion by the radial expansion.

It can be seen from Figure 3 that the overall, radial, and axial expansion ratios of final product were $4,11.5$, and 0.35 , respectively. Those ratios indicated that extrudates tend to expand radially rather that longitudinally. Similar phenomena were also reported by Sokhey et $\mathrm{al}^{20}$ and Alvarez-Martinez et al. ${ }^{29}$ During expansion, bubble growth increases the porosity of the extrudate, resulting in an increase in overall expansion. The overall expansion means an increase in the extrudate volume for a given extrudate mass. As the extrudate had a cylindrical shape, the volume of the extrudate was determined by its diameter and length. For a given extrudate volume and diameter, the length of extrudate generated at a given time step is determined by the downstream velocity of the extrudate. As the axial expansion ratio was smaller than 1 , the downstream velocity of the extrudate should be smaller than that of melt at the exit of die. Therefore, the bubble growth was not the only factor governing the expansion process. Die swell due to the viscoelastic behavior of the melt should be an important factor for explaining the decrease of downstream velocity of extrudate during expansion.

\section{Die Swell}

The histories of extrudate downstream velocity during expansion are shown in Figure 4. It can be seen that there are three segments to the velocity curve: (1) constant downstream velocity of fully developed non-Newtonian flow inside the die, (2) decrease in downstream velocity at the exit of the die, and (3) constant downstream velocity of free-surface flow of extrudate. 


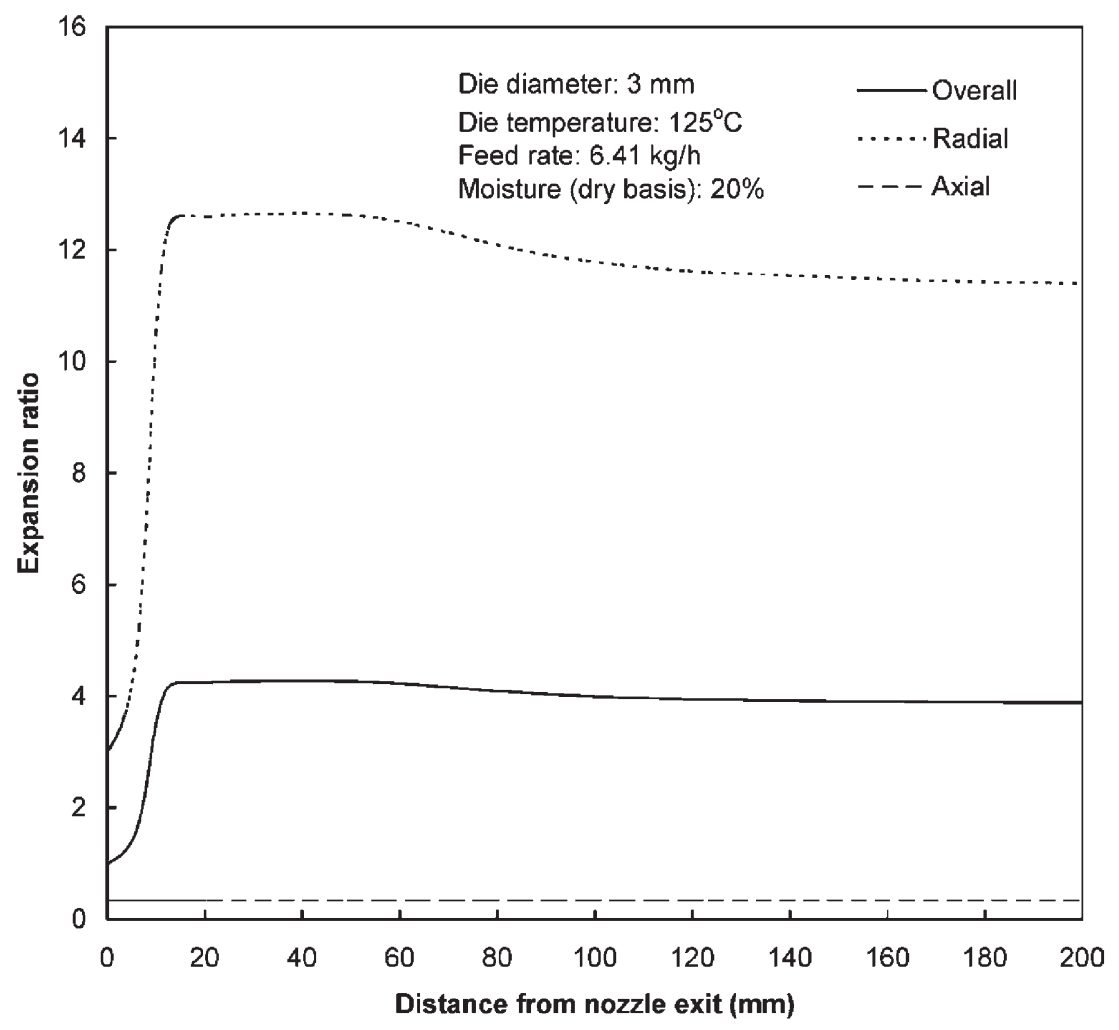

Figure 3. Histories of predicted overall, radial, and axial expansion ratios during expansion for starch-based foams.

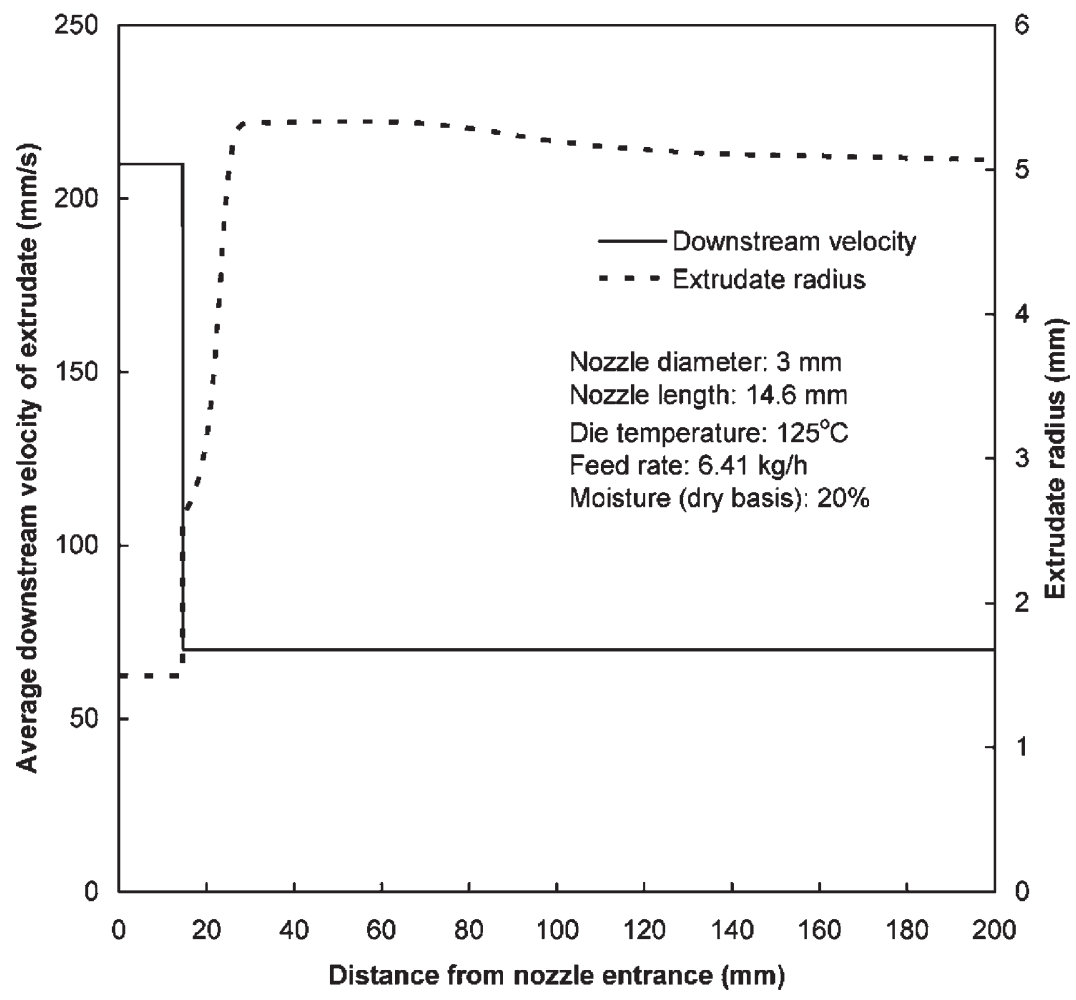

Figure 4. Histories of predicted average downstream velocity and radius of extrudate during expansion for starch-based foams. 


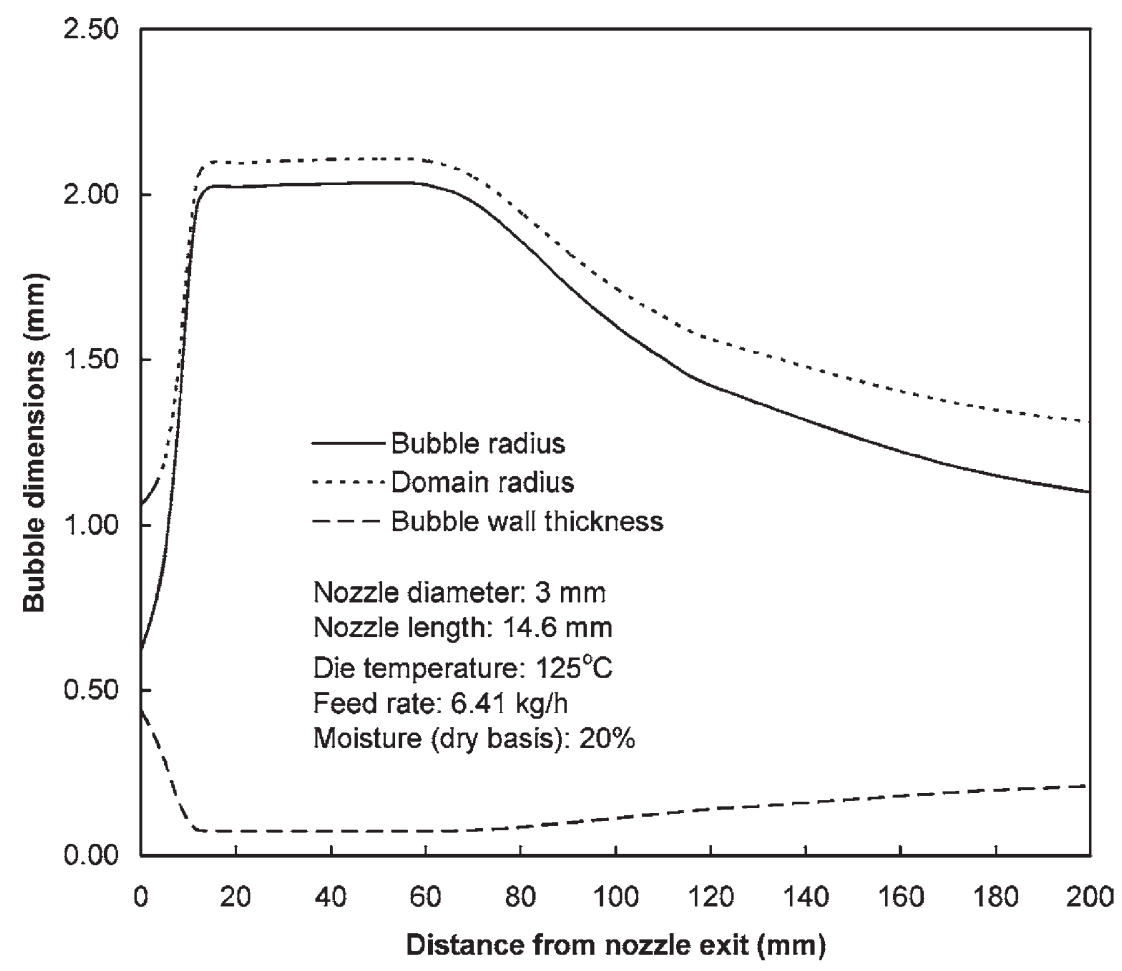

Figure 5. Histories of predicted bubble radius, domain radius, and thickness of bubble shell for a bubble domain in the central region of the extrudate during expansion for starch-based foams.

During expansion, a significant decrease in the velocity of extrudate takes place at the die exit. When the melt flows through the die, there exists a high shear rate due to the high viscosity of the melt and the friction effects of the die wall. The downstream velocity thus follows a parabolic distribution (creeping flow) in the radial direction as shown in Figure 1a. When the melt exits from the die, the extrudate experiences free-surface flow. In this case, the stress field of the extrudate relaxes from a high value inside the die to an isotropic stress field of the free flow. The velocity profile thus changes from the parabolic shape inside the die to a final uniform velocity distribution as shown in Figure 1a. The relaxation of velocity pro- file and stress fields is balanced by viscous forces in the extrudate, which follows momentum conservation in the extrudate. As the mass flow rate of the extrudate is given, the decrease in the downstream velocity of the extrudate, due to the relaxation of velocity profile and stress field, will cause an increase in the diameter of the extrudate, as shown in Figure 4. A similar mechanism for die swell of viscoelastic fluids has been reported previously. ${ }^{17-19}$

\section{Bubble Growth}

Figure 5 gives the bubble radius, domain radius, and thickness of bubble shell versus axial distance of extrudate. The bubble radius increased very slowly near the die exit and very rapidly toward the end of expansion. At the beginning of expansion, the pressure difference, $\Delta P$, which contributes to the bubble growth, was small due to the high initial surface tension and yield stress imposed on the bubble shell. Both surface tension and yield stress decreased with the increase of bubble radius, resulting in the increase of pressure difference and the bubble expansion rate. The increase of bubble radius simultaneously caused the increase in domain radius and decrease in shell thickness. At the end of expansion, the domain radius approached the bubble radius. This means the shell thickness of the bubble cell became very small. In this case, the bubble might be ruptured depending on the moisture and temperature of the domain. The change of domain radius further contributed to the expansion of extrudate as shown in Figure 3.

When vapor pressure inside of the bubble was smaller than the outer pressure due to the decrease of 


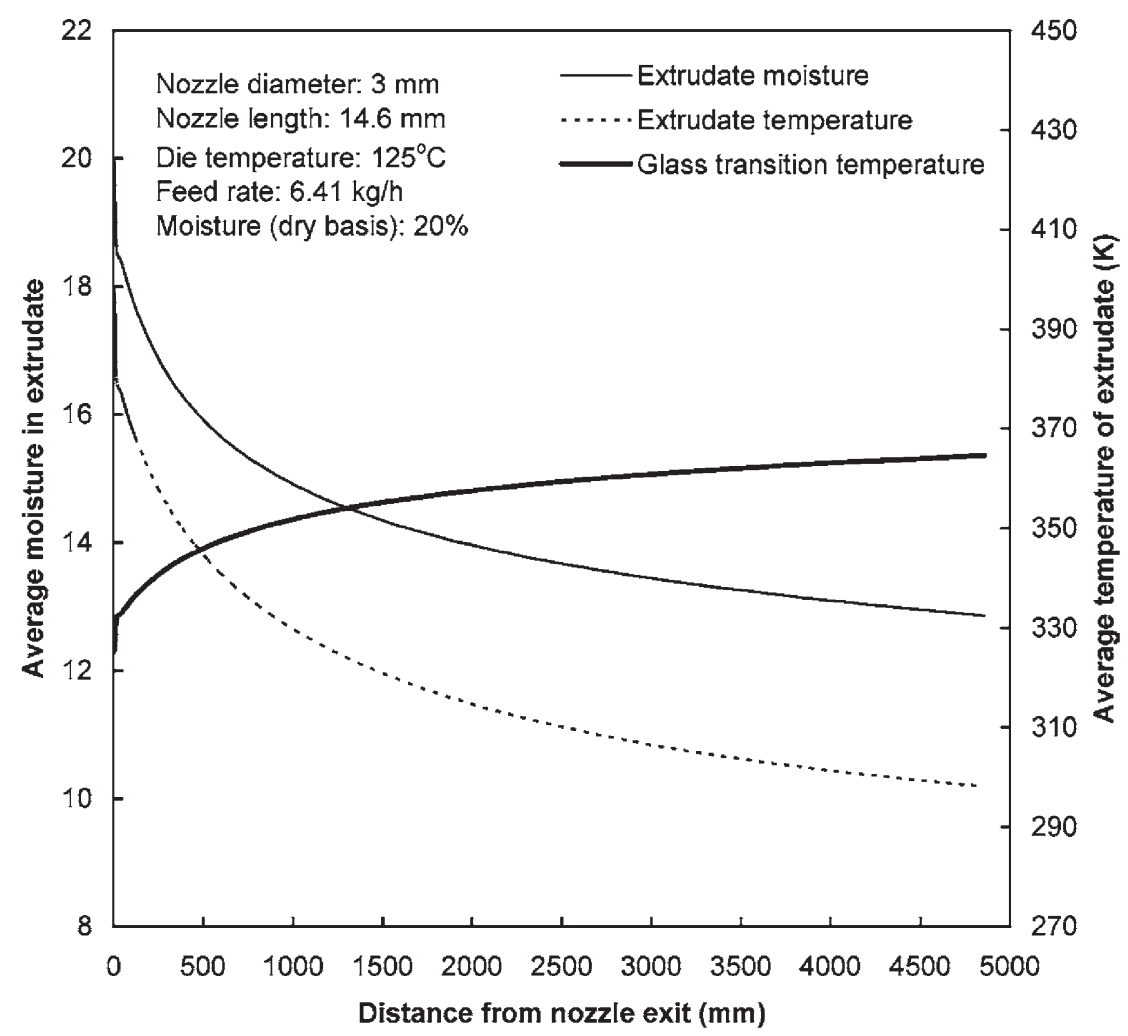

Figure 6. Histories of predicted average moisture, extrudate temperature, and glass transition temperature during expansion for starch-based foams.

the extrudate temperature, bubble expansion stopped and bubbles shrank due to further decrease in extrudate temperature. The shrinkage of the bubbles contributed to the shrinkage of the extrudate as shown in Figure 3.

Furthermore, during expansion, bubble rupture occurs. When bubbles rupture, they lose their ability to expand and shrink. As shown in Figure 5, the radius of bubbles in the center region of the final extrudate may range from the initial value of $0.6 \mathrm{~mm}$ to the maximum value of $2 \mathrm{~mm}$. Cisneros and Kokini ${ }^{21}$ reported that the visible bubbles in the extrudate were 1-2 mm diameter. Warburton et al. ${ }^{30}$ reported average pore diameters of $2-3 \mathrm{~mm}$ in starch extrudates.

\section{Moisture Loss and Temperature Drop of Extrudate}

During expansion, as bubbles in the extrudate grow in size, water will diffuse to the bubble surface and evaporate on the bubble surface to maintain the equilibrium of vapor in the bubbles. Latent heat of evaporation causes a decrease in the bubble domain and the solidification of melt matrix. Figure 6 gives the histories of mass average moisture and temperature of the extrudate during expansion. If evaporated vapor is totally entrapped in the bubbles for increasing the volume of the bubbles, the moisture loss during expansion should be very small as the specific volume of vapor is very big. For example, if the vapor is assumed to be an ideal gas, the specific volume of saturation water vapor should be about $0.6 \mathrm{~m}^{3} / \mathrm{kg}$ at $140^{\circ} \mathrm{C}$. If the initial and final specific volumes of the extrudate are about $0.0008 \mathrm{~m}^{3} /$ $\mathrm{kg}$ (corresponding to a density of approximately $1200 \mathrm{~kg} / \mathrm{m}^{3}$ ) and $0.003 \mathrm{~m}^{3} / \mathrm{kg}$ (corresponding to a density of approximately $330 \mathrm{~kg} / \mathrm{m}^{3}$ ), respectively, moisture loss should be only $0.35 \%$ of the weight of the dried extrudate.

However, the moisture loss was much higher in a practical extrusion operation. As shown in Table II, the measured residual moisture in the final extrudate was $8-10 \%$ when the initial moisture content of the melt was 20\% (dry basis). Therefore, a large amount of water vapor was released from the extrudate to the environment through ruptured bubbles. When a bubble is ruptured, the moisture on the hot shell of bubbles will rapidly be flashed off from the porous and moist melt matrix due to its large surface area available for water evaporation. 
The vaporization of moisture in the extrudate causes a rapid drop in the extrudate temperature as shown in Figure 6. This phenomenon of cooling during expansion is similar to the rapid cooling of porous and moist foods using vacuum technology due to high moisture evaporation. ${ }^{31}$ It can be assumed that $1 \%$ of moisture loss can cause a temperature drop of about $12.5^{\circ} \mathrm{C}$ for the extrudate (equation: $\Delta T$ / $(\Delta m / m) \%=\lambda / 100 c_{p^{\prime}}$ latent heat: $\lambda=2250 \mathrm{~kJ} / \mathrm{kg}$ and specific heat capacity: $c_{\mathrm{p}}=1.75 \mathrm{~kJ} / \mathrm{kg}^{\circ} \mathrm{C}$ ). Therefore, a moisture loss of $10 \%$ (dry basis) can decrease the temperature of an extrudate from $150^{\circ} \mathrm{C}$ to $25^{\circ} \mathrm{C}$.

When the extrudate is below the glass transition temperature of the starch, the starch melt will solidify. It can be seen from Figure 6 that the extrudate temperature was below the glass transition temperature at the location $500 \mathrm{~mm}$ from the nozzle exit for the predicted case of expansion. Solidification fixed the shape of the bubble cells and extrudate. After solidification, the bubbles and the extrudate finally lost their abilities to expand and shrink.

\section{Conclusions}

A mathematical model was developed to describe bubble growth, die swell, and transport phenomena in the extrudate during the expansion process of starch-based foams. The standard deviations between the predicted and experimental radius, density, and residual moisture of final extrudates were $16.7 \%$, $11.2 \%$, and $39.3 \%$, respectively.

The predictions show a significant decrease in downstream velocity of the extrudate occurs at the die exit when the melt changes from a no-slip, nonNewtonian flow in the die channel to a free-surface flow. The decrease of the downstream velocity causes die swell, resulting in radial expansion. Bubble radii increase due to the expansion of superheated water vapor in the bubbles and further expand the extrudate.

During expansion, there is a rapid decrease in the moisture content of the extrudate due to the release of vapor from the ruptured bubbles. The predicted moisture loss from the final extrudate was about $8 \%$ of the solid weight if the initial moisture content of the melt was $20 \%$ (dry basis). The local vaporization of moisture in the extrudate rapidly cooled the extrudate from a high initial temperature (i.e., $125^{\circ} \mathrm{C}$ ) to an ambient temperature (i.e., $25^{\circ} \mathrm{C}$ ).

In order to improve the accuracy of the predic-

tions, more research is needed to determine initial porosity and bubble number density of the melt, and to select suitable correlations for rheological properties of low shear rate flow, elastic modulus, flow yield stress, and cell wall failure stress.

\section{Acknowledgments}

A contribution of the University of Nebraska Agricultural Research Division, Lincoln, NE. Journal Series no. 14280. This research was supported in part by funds provided through the Hatch Act. This study was conducted at the Industrial Agricultural Products Center, University of Nebraska, Lincoln, NE, USA, under a contract grant sponsored by the U.S. Department of Energy.

\section{Nomenclature}

$A_{\mathrm{es}}$
$a_{\mathrm{w}}$
$c_{\mathrm{p}}$
$\Delta c_{\mathrm{p} 1}$

$\Delta c_{\mathrm{p} 2}$

$D_{\mathrm{w}}$

$D_{\mathrm{d}}$

E

$f_{\mathrm{o}}$

$\Delta f_{\mathrm{o}}$

G

$h_{\mathrm{e}}$

$h_{\mathrm{m}}$

$h_{\mathrm{t}}$

$h_{\mathrm{t}}$

K

$L_{\mathrm{d}}$

$\Delta L$

M

$\dot{\mathrm{m}}_{\mathrm{s}}$

$m_{\mathrm{s}^{\prime}} i$
Surface area of the extrudate $\left(\mathrm{m}^{2}\right)$

Water activity

Specific heat capacity (kJ/(kg K))

Change in specific heat capacity at $T_{\mathrm{g} 1}(\mathrm{~kJ} /(\mathrm{kg}$ K))

Change in specific heat capacity at $T_{\mathrm{g} 2}(\mathrm{~kJ} /(\mathrm{kg}$ K))

Moisture diffusivity $\left(\mathrm{m}^{2} / \mathrm{s}\right)$

Die diameter $(\mathrm{m})$

Elastic modulus of materials surrounding a bubble $(\mathrm{Pa})$

Number fraction of open cells

Change of number fraction of open cells

Constant in equation of state for water vapor $\left(\mathrm{m}^{3} \mathrm{~Pa} /(\mathrm{kg} \mathrm{K})\right)$

Evaporation coefficient of water $(\mathrm{kg} /(\mathrm{Pa}$ $\left.\mathrm{m}^{2} \mathrm{~s}\right)$ )

Mass transfer coefficient on the extrudate surface $(1 / \mathrm{m})$

Total heat transfer coefficient on the extrudate surface $\left(\mathrm{W} /\left(\mathrm{m}^{2} \mathrm{~K}\right)\right)$

Consistency in power law of viscosity $\left(\mathrm{Ns}^{n} /\right.$ $\mathrm{m}^{2}$ )

Die Length (m)

Length of extrudate generated at a time step (m)

Mass fraction

Mass flow rate of dry solid in the melt $(\mathrm{kg} / \mathrm{s})$

Total mass of dry solid in the $i$-th layer of the selected extrudate piece $(\mathrm{kg})$ 


\begin{tabular}{|c|c|}
\hline$\dot{m}_{\mathrm{s}^{\prime}} i$ & $\begin{array}{l}\text { Mass flow rate of dry solid in the } i \text {-th layer of } \\
\text { the extrudate }(\mathrm{kg} / \mathrm{s})\end{array}$ \\
\hline$\dot{m}_{\mathrm{t}}$ & Total mass flow rate of melt $(\mathrm{kg} / \mathrm{s})$ \\
\hline$\dot{m}_{\mathrm{v}}$ & $\begin{array}{l}\text { Mass cumulative rate of vapor in a bubble } \\
(\mathrm{kg} / \mathrm{s})\end{array}$ \\
\hline$m^{\prime}{ }_{\mathrm{w}, \mathrm{es}}$ & $\begin{array}{l}\text { Moisture evaporation rate on the extrudate } \\
\text { surface }(\mathrm{kg} / \mathrm{s})\end{array}$ \\
\hline$\Delta m_{v}$ & Change of vapor mass in a bubble $(\mathrm{kg})$ \\
\hline$n$ & Shear rate exponent in power-law of viscosity \\
\hline$N_{\mathrm{b}}$ & $\begin{array}{l}\text { Bubble density (bubble number } / \mathrm{kg} \text { solid } \\
\text { melt) }\end{array}$ \\
\hline$N_{\mathrm{e}}$ & Total number of layers in extrudate \\
\hline$P$ & Pressure $(\mathrm{Pa})$ \\
\hline$P^{*}$ & Saturation water pressure (Pa) \\
\hline$P_{\mathrm{e}}$ & $\begin{array}{l}\text { Reduction in pressure difference by elastic } \\
\text { stress }(\mathrm{Pa})\end{array}$ \\
\hline$P_{i}$ & Pressure in the bubble $(\mathrm{Pa})$ \\
\hline$P_{\mathrm{s}}$ & Pressure at the surface of a domain $(\mathrm{Pa})$ \\
\hline$P_{\mathrm{t}}$ & $\begin{array}{l}\text { Reduction in pressure difference by surface } \\
\text { tension }(\mathrm{Pa})\end{array}$ \\
\hline$P_{\mathrm{y}}$ & Reduction in pressure by yield stress (Pa) \\
\hline$\Delta P$ & $\begin{array}{l}\text { Pressure difference inside and outside of a } \\
\text { bubble }(\mathrm{Pa})\end{array}$ \\
\hline$\dot{q}$ & $\begin{array}{l}\text { Inner heat generation rate per volume of ex- } \\
\text { trudate }\left(\mathrm{W} / \mathrm{m}^{3}\right)\end{array}$ \\
\hline$q_{\text {es }}^{\prime}$ & $\begin{array}{l}\text { Evaporation heat transfer rate on the extru- } \\
\text { date surface }\left(\mathrm{W} / \mathrm{m}^{2}\right)\end{array}$ \\
\hline$R$ & Radius of a bubble (m) \\
\hline$R^{\prime}$ & Radius of a domain (m) \\
\hline$\dot{R}$ & Expansion rate of bubble radius (m/s) \\
\hline$R_{\mathrm{d}}$ & Radius of a die (m) \\
\hline$R_{\mathrm{e}}$ & Radius of extrudate $(\mathrm{m})$ \\
\hline$\Delta R$ & Change of bubble radius $(\mathrm{m})$ \\
\hline$S_{\mathrm{w}}$ & Bubble wall stress $(\mathrm{Pa})$ \\
\hline$S_{\mathrm{f}}$ & Failure stress of bubble wall $(\mathrm{Pa})$ \\
\hline$T$ & Temperature (K) \\
\hline$T_{\mathrm{g}}$ & $\begin{array}{l}\text { Glass transition temperature of extrudate } \\
\text { melt }(\mathrm{K})\end{array}$ \\
\hline$T_{\mathrm{g} 1}$ & Glass transition temperature of the water $(\mathrm{K})$ \\
\hline$T_{\mathrm{g} 2}$ & Glass transition temperature of starch $(\mathrm{K})$ \\
\hline$\Delta T$ & Change of domain temperature $(\mathrm{K})$ \\
\hline$\Delta t$ & Time step (s) \\
\hline$u$ & Velocity of melt flow $(\mathrm{m} / \mathrm{s})$ \\
\hline$v$ & Specific volume of water vapor $\left(\mathrm{m}^{3} / \mathrm{kg}\right)$ \\
\hline$V_{\mathrm{d}}$ & Volume of a bubble domain $\left(\mathrm{m}^{3}\right)$ \\
\hline
\end{tabular}
W Thickness of bubble wall (m)
$X_{\mathrm{w}} \quad$ Moisture content (\% dry base)
$\Delta X_{\mathrm{w}, \mathrm{bs}}$ Change of moisture on the bubble surface

\section{Greek Letters}

$\lambda \quad$ Latent heat caused by water evaporation in the extrudate $(\mathrm{kJ} / \mathrm{kg})$

$\tau \quad$ Flow yield stress $(\mathrm{Pa})$

$\sigma \quad$ Surface tension $(\mathrm{N} / \mathrm{m})$

$\sigma^{\prime} \quad$ Shear stress $(\mathrm{Pa})$

$\gamma \quad$ Shear rate $(1 / \mathrm{s})$

$\eta \quad$ Effective viscosity (Pa s)

$\xi \quad$ Variations of $K$ along the bubble surface to the outer surface of a domain $\left(\mathrm{Ns}^{\mathrm{n}} / \mathrm{m}^{2}\right)$

$\rho_{\mathrm{m}} \quad$ Density of melt $\left(\mathrm{kg} / \mathrm{m}^{3}\right)$

$\rho_{\mathrm{s}} \quad$ Solid density of starch $\left(\mathrm{kg} / \mathrm{m}^{3}\right)$

$\varphi \quad$ Porosity or volume fraction (\%)

$\beta \quad$ Term defined by Equation (15)

a $\quad$ Term defined by Equation (14)

\section{Subscripts and Superscripts}

$\begin{array}{ll}0 & \text { Initial } \\ \mathrm{a} & \text { Ambient } \\ \text { aver } & \text { Average value } \\ \mathrm{b} & \text { Bubble } \\ \mathrm{bs} & \text { Bubble surface } \\ \mathrm{d} & \text { Die } \\ \mathrm{d} ' & \text { Domain } \\ \mathrm{d} \text { 's } & \text { Domain surface } \\ \mathrm{e} & \text { Extrudate } \\ \mathrm{es} & \text { Extrudate surface } \\ i & \text { The layer number in the extrudate } \\ \mathrm{K} & \text { Kelvin temperature } \\ \mathrm{m} & \text { Melt } \\ \mathrm{o} & \text { Open } \\ \mathrm{s} & \text { Starch } \\ t & \text { Time } \\ \Delta t, n & \text { Time step } \\ \mathrm{v} & \text { Vapor } \\ \mathrm{w} & \text { Water }\end{array}$




\section{References}

1. Huang, J. -C.; Shetty, A. S.; Wang, M.-S. Adv Polym Technol 1990, 10, 23-30.

2. Averous, L.; Fauconnier, N; Moro, L.; Fringant, C. J Appl Polym Sci 2000, 76, 1117-1128.

3. Gordon, S. H.; Imam, S. H.; Shogren, R. L.; Govind, N. S.; Greene, R. V. J Appl Polym Sci 2000, 76, 1767-1776.

4. Matzinos, P.; Bikiaris, D.; Kokkou, S.; Panayiotou, C. J Appl Polym Sci 2001, 79, 2548-2557.

5. Ke, T.; Sun, X. S. J Appl Polym Sci 2003, 88, 2947-2955.

6. Souza, R. C. R.; Andrade, C. T. Adv Polym Technol 2002, 21, 17-24.

7. Fang, Q.; Hanna, M. A. Ind Crops Prod 2001, 13, 219-227.

8. Fang, Q.; Hanna, M. A. Bioresour Technol 2001, 78, 115-122.

9. Lee, C. H.; Lee, K. J.; Jeong, H. G.; Kim, S. W. Adv Polym Technol 2000, 19, 97-112.

10. Goel, S. K.; Beckman, E. J. AIChE J 1995, 41, 357-367.

11. Alavi, S. H.; Razvi, S. S. H.; Harriott, P. Food Res Int 2003, 36, 309-319.

12. Alavi, S. H.; Razvi, S. S. H.; Harriott, P. Food Res Int 2003, 36, 321-330.

13. Yang, W. J.; Yeh, H. C. AIChE J 1966, 12, 927-931.

14. Street, J. R.; Fricke, A. L.; Reiss, L. P. Ind Eng Chem Fundam 1971, 10, 54-64.

15. Fan, J.; Mitchell, J. R.; Blashard, J. M. V. J Food Eng 1994, 23, 337-356.

16. Schwartzberg, H. G.; Wu, J. P. C.; Nussinovitch, A.; Mugerwa, J. J Food Eng 1995, 25, 329-372.

17. Crochet, M. J.; Keunings, R. J Non-Newtonian Fluid Mech 1982, 10, 339-356.

18. Chang, R. Y.; Yang, W. L. J Non-Newtonian Fluid Mech 1994, 51, 1-19.
19. Gast, L.; Ellingson, W. Int J Numer Methods Fluids 1999, 29, 1-18.

20. Sokhey, A. S.; Ali, Y.; Hanna, M. A. J Food Eng 1997, 31, 251-261.

21. Cisneros, F. H.; Kokini, J. L. J Food Eng 2002, 51, 139-149.

22. Harper, J. M. Extrusion of Foods; CRC Press: Boca Raton, FL, 1981; Vol. 1.

23. Cummings, D. A.; Okos, M. R. Trans ASAE 1983, 26, 1988-1993.

24. Wang, L. J.; Sun, D. W. Trends Food Sci Technol 2001, 12, 174-184.

25. Rahman, S. Food Properties Handbook; CRC Press: Boca Raton, FL, 1995.

26. Kalichevsky, M. T.; Jaroszkiewicz, E. M.; Blanshard, J. M. V. Polymer 1993, 34, 346-358.

27. Padmanaban, M.; Bhattacharya, M. J Food Eng 1993, 18, 335-349.

28. Karathanos, V. T.; Saravacos, G. D. J Food Eng 1993, 18, 259-280.

29. Alvarez-Martinez, L.; Kondury, K. P.; Harper, J. M. J Food Sci 1988, 53, 609-615.

30. Warburton, S. C.; Donald, A. M.; Smith, A. C. J Mater Sci 1990, 25, 4001-4007.

31. Wang, L. J.; Sun, D. W. Trans ASAE 2003, 46, 107-115.

32. Parker, R.; Ollett, A.; Lai-Fook, R. A.; Smith, A. C. In Rheology of Food Biological and Pharmaceutical Materials; Carter, R. E. (Ed.); Elsevier: London, 1989.

33. Maroulis, Z. B.; Shah, K. K.; Saravacos, G. D. J Food Sci 1991, 56, 773-776.

34. Van der Lijn, J. (1976). Simulation of heat and mass-transfer in spray drying; PhD Thesis, Agricultural University of Wageningen, The Netherlands, pp. 77-80 (as referred in Schwartzberg et al. [16] and Alavi et al. [11]). 